\title{
Vibration analysis of a tapered beam with exponentially varying thickness resting on Winkler foundation using the differential transform method
}

\author{
Sayad Boreyri ${ }^{1}{ }^{*}$, Pouya Mohtat $^{2}$, Mohamad Javad Ketabdari ${ }^{1}$, Ali Moosavi ${ }^{3}$ \\ ${ }^{1}$ Department of Marine Technology, Amirkabir University of Technology, Tehran, Iran \\ ${ }^{2}$ Department of Mechanical Engineering, Sharif University of Technology, Tehran, Iran \\ ${ }^{3}$ Department of Mathematics, Sharif University of Technology, Tehran, Iran \\ *Corresponding author E-mail: Sayyad.Boreyri@aut.ac.ir
}

Copyright $\odot 2014$ Sayad Boreyri et al. This is an open access article distributed under the Creative Commons Attribution License, which permits unrestricted use, distribution, and reproduction in any medium, provided the original work is properly cited.

\begin{abstract}
In this paper, free vibration of a new type of tapered beam, with exponentially varying thickness, resting on a linear foundation is analyzed. The solution is based on a semi-analytical technique, the differential transform method (DTM). Applying DTM, nonlinear partial differential equations of the varying thickness beam are transformed into algebraic equations, which are then solved to obtain the solution. An Euler-Bernoulli beam with a number of boundary conditions and different exponential factor is taken into account. Results have been compared to the 4th order Runge-Kutta, and where possible with DQEM and analytical solution. These comparisons prove the preciseness of this method, based on which DTM can be considered as a powerful framework for eigenvalue analysis of new type of tapered beams.
\end{abstract}

Keywords: Free Vibration, Exponential (Tapered) Beam, Winkler Foundation, Differential Transform Method (DTM).

\section{Introduction}

The study of vibration of a beam on an elastic foundation has been a field of great interest to many researchers in civil and mechanical engineering, including a pile embedded on the soil and a beam rested on the ground. There are a number of foundation models, among which Winkler model is the most well-known and widely used mechanical model.

Dynamic behavior of a beam on elastic foundation has been the subject of many researches in the past. Lin [1] was among the first who dealt with the vibration of a beam on elastic supports. Valsangkar and Pradhanang [2] and Franciosi and Masi [3] investigated Euler-Bernoulli beam on two-parameter model soil foundation, while De Rosa [4] and Ruta [5] did the same for Timoshenko beams. Chen employed the differential quadrature element method (DQEM), to investigate the vibration of beams on Winkler [6] and Pasternak [7] foundations. Hosing et al. [8] have solved natural flexural vibrations of a continuous beam on discrete elastic support. DTM, first proposed by Zhou [9], was employed to find free vibration of a constant thickness beam on elastic soil by Catal [10] and Balkaya et al. [11] .

Other than the above, in recent years, a few researches have been conducted concentrating on exponential characteristic of beams. Awodola [12] solve the problem of vibration of a beam under exponentially varying magnitude moving load. Mao and Pietrzko [13] used the Adomian decomposition method (ADM) to examine the free vibration of a beam with a continuously exponential variation of width and a constant thickness along the length.

In this paper, we investigate natural frequencies of free vibration of an Euler-Bernoulli beam with exponential thickness supported by a Winkler foundation. In section 2, Normalized governing equations are derived, and DTM is briefly introduced. In section 3 , the solution procedure is fully explained, and in section 4 semi-analytical results based upon the derived formula are presented. Finally, the authors draw a conclusion based on the obtained results in section 5 . 


\section{Mathematical formulation}

\subsection{Equation of motion}

Vibration of an exponential beam resting on Winkler foundation as shown in Fig.1 is analyzed here. The motion of an Euler-Bernoulli beam can be characterized by the following equation:

$\frac{\partial^{2}}{\partial \mathrm{x}^{2}}\left(\mathrm{EI}(\mathrm{x}) \frac{\partial^{2} \mathrm{u}}{\partial \mathrm{x}^{2}}\right)+\rho \mathrm{A}(\mathrm{x}) \frac{\partial^{2} \mathrm{u}}{\partial \mathrm{t}^{2}}+\mathrm{ku}=0$

In which $\rho, A(x), u(x, t), E$ and $I(x)$ are the mass density $\left(\mathrm{kg} / \mathrm{m}^{3}\right)$, cross-sectional area $\left(\mathrm{m}^{2}\right)$, transverse deflection $(\mathrm{m})$, Young's Modulus $(\mathrm{Pa})$, and area moment of inertia about the neutral axis $\left(\mathrm{m}^{4}\right)$, respectively. $\mathrm{k}$ is the spring constant in Winkler model soil, and it is simulated by "a series of closely spaced, mutually independent, linear elastic vertical springs" [11].

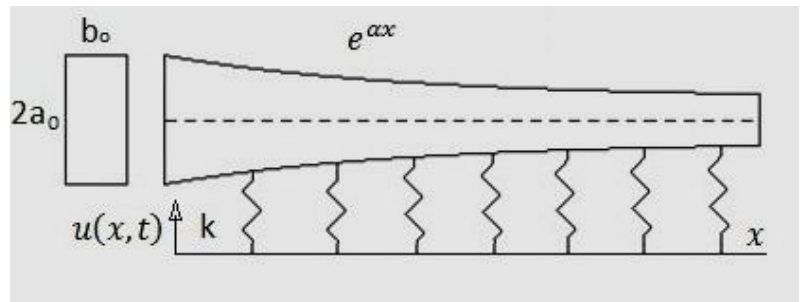

Fig. 1: Geometry of the Exponential Beam on a Linear Foundation

For a constant $\mathrm{E}$ and a variable cross section with respect to the horizontal axis (x), as illustrated in Fig.1, we can expand eq. (1) to obtain:

$\frac{\partial^{4} \mathrm{u}}{\partial \mathrm{x}^{4}}+2 \mathrm{E} \frac{\partial \mathrm{I}}{\partial \mathrm{x}} \frac{\partial^{3} \mathrm{u}}{\partial \mathrm{x}^{3}}+\mathrm{E} \frac{\partial^{2} \mathrm{I}}{\partial \mathrm{x}^{2}} \frac{\partial^{2} \mathrm{u}}{\partial \mathrm{x}^{2}}+\rho \mathrm{A}(\mathrm{x}) \frac{\partial^{2} \mathrm{u}}{\partial \mathrm{t}^{2}}+\mathrm{ku}=0$

The system is assumed to have harmonic vibration with $\mathrm{u}(\mathrm{x}, \mathrm{t})=\mathrm{U}(\mathrm{x}) \sin (\omega \mathrm{t})$. Thus, the solution can be expressed as: $E I \frac{d^{4} \mathrm{U}}{d x^{4}}+2 E \frac{d I}{d x} \frac{d^{3} \mathrm{U}}{d x^{3}}+E \frac{d^{2} I}{d x^{2}} \frac{d^{2} \mathrm{U}}{d x^{2}}-2 \omega^{2} \rho A(x) U(x)+k U(x)=0$

Denoting the beam's breadth and depth by $\mathrm{b}=\mathrm{b}_{0}$ and $\mathrm{a}=2 \mathrm{a}_{0} \mathrm{e}^{\alpha \mathrm{x}}$, respectively, one can easily write:

$\mathrm{A}=\mathrm{ba}=2 \mathrm{a}_{0} \mathrm{~b}_{0} \mathrm{e}^{\alpha \mathrm{x}} \mathrm{I}=\frac{1}{12} \mathrm{ba}^{3}=\frac{2}{3} \mathrm{~b}_{0} \mathrm{a}_{0}^{3} \mathrm{e}^{3 \alpha \mathrm{x}}$

Where $\alpha$ is a factor to show exponential rate of the beam. Substituting these relations into Eq. (3) the following relation is obtained:

$\frac{2}{3} E b_{0} a_{0}^{3} e^{3 \alpha x} \frac{\partial^{4} U}{\partial x^{4}}+4 E b_{0} a_{0}^{3} \alpha e^{3 \alpha x} \frac{\partial^{3} U}{\partial x^{3}}+6 E b_{0} a_{0}^{3} \alpha^{2} e^{3 \alpha x} \frac{\partial^{2} U}{\partial x^{2}}+2 \rho b_{0} a_{0} e^{\alpha x} \omega^{2} U+k U=0$

\subsection{Normalization}

Normalized parameters for the exponential beam on linear foundation can be determined by defining:

$\xi=\frac{\mathrm{x}}{\mathrm{L}}, \overline{\mathrm{U}}=\frac{\mathrm{U}}{\mathrm{L}}, \beta=3 \alpha \mathrm{L}, \lambda=\frac{3 \mathrm{~kL}^{4}}{2 \mathrm{~Eb}_{0} \mathrm{a}_{0}^{3}}, \gamma=\frac{3 \rho \mathrm{L}^{4} \omega^{2}}{\mathrm{Ea}_{0}^{2}}$,

Where $\gamma$ is the normalized natural frequency? Applying these parameters to Eq. (4) the non-dimensional form of equation of motion is in the form of:

$\mathrm{e}^{\beta \xi} \frac{\mathrm{d}^{4} \overline{\mathrm{U}}}{\mathrm{d} \xi^{4}}+2 \beta \mathrm{e}^{\beta \xi} \frac{\mathrm{d}^{3} \overline{\mathrm{U}}}{\mathrm{d} \xi^{3}}+\beta^{2} \mathrm{e}^{\beta \xi} \frac{\mathrm{d}^{2} \overline{\mathrm{U}}}{\mathrm{d} \xi^{2}}+\left(\lambda-\gamma \mathrm{e}^{\frac{1}{3} \beta \xi}\right) \overline{\mathrm{U}}=0$

\subsection{Differential Transform Method}

The DTM is based on the Taylor series expansion. However, the main advantage of this method is that it computes the terms of the equation with a recursive formulation which dramatically reduces the costs of calculations. DT technique converts differential equations to a set of algebraic equations. By solving these equations, a closed-form or a recursive solution can be obtained.

The Taylor series expansion of a function $\mathrm{f}(\mathrm{x})$ about a point $\mathrm{x}=\mathrm{x}_{0}$ is given by:

$\mathrm{f}(\mathrm{x})=\sum_{\mathrm{k}=0}^{\infty} \mathrm{F}(\mathrm{k})\left(\mathrm{x}-\mathrm{x}_{0}\right)^{\mathrm{k}}$

$\mathrm{F}(\mathrm{k})=\frac{1}{\mathrm{k} !}\left[\frac{\mathrm{d}^{\mathrm{k}} \mathrm{d}}{\mathrm{dy}}\right]_{\mathrm{x}=\mathrm{x}_{0}}$

Uppercase and lowercase letters were used for transformed function $F(k)$ ( $\mathrm{k}^{\text {th }}$ order Differential transform) and the original function $f(x)$, respectively. In actual applications, computing a finite number of terms suffices:

$\mathrm{f}(\mathrm{x})=\sum_{\mathrm{k}=0}^{\mathrm{N}} \mathrm{F}(\mathrm{k})\left(\mathrm{x}-\mathrm{x}_{0}\right)^{\mathrm{k}}$

The above equation is approximately true, under the condition that $\sum_{k=N+1}^{\infty}\left(x-x_{0}\right)^{k} F(k)$ becomes negligibly small. The appropriate value for $N$ depends on the rate of convergence of the series and the number of natural frequencies to 
be calculated. Some fundamental theorems of DTM are listed in table 1 . Their derivation and proofs are fully covered in [14], [15], and [16].

Table 1: Fundamental Operations of One-Dimensional DTM

\begin{tabular}{ll}
\hline Original Function & Transformed Function \\
\hline $\boldsymbol{f}(\boldsymbol{x})=\boldsymbol{\alpha u}(\boldsymbol{x}) \pm \boldsymbol{\beta} \boldsymbol{v}(\boldsymbol{x})$ & $\boldsymbol{F}(\boldsymbol{k})=\boldsymbol{\alpha} \boldsymbol{U}(\boldsymbol{k}) \pm \boldsymbol{\beta} \boldsymbol{V}(\boldsymbol{k})$ \\
$\boldsymbol{f}(\boldsymbol{x})=\boldsymbol{u}(\boldsymbol{x}) \boldsymbol{v}(\boldsymbol{x})$ & $\boldsymbol{F}(\boldsymbol{k})=\sum_{\boldsymbol{n}=\mathbf{0}}^{\boldsymbol{U}} \boldsymbol{U}(\boldsymbol{n}) \boldsymbol{V}(\boldsymbol{k}-\boldsymbol{n})$ \\
$\boldsymbol{f}(\boldsymbol{x})=\frac{\boldsymbol{d}^{\boldsymbol{m}} \boldsymbol{u}(\boldsymbol{x})}{\boldsymbol{d} \boldsymbol{x}^{\boldsymbol{m}}}$ & $\boldsymbol{F}(\boldsymbol{k})=(\boldsymbol{k}+\mathbf{1})(\boldsymbol{k}+2) \ldots(\boldsymbol{k}+\boldsymbol{m}) \boldsymbol{U}(\mathbf{k}+\boldsymbol{m})$ \\
$\boldsymbol{f}(\boldsymbol{x})=\boldsymbol{x}^{\boldsymbol{m}}$ & $\boldsymbol{\delta}(\boldsymbol{k}-\boldsymbol{m})$ \\
$\boldsymbol{f}(\boldsymbol{x})=\boldsymbol{e x p}(\lambda \boldsymbol{x})$ & $\frac{\lambda^{\boldsymbol{k}}}{\boldsymbol{k} !}$ \\
\hline
\end{tabular}

\subsection{Solution procedure}

First, we take the differential transform of Eq. (6) which represents the equation of motion for an exponential EulerBernoulli beam supported on Winkler foundation. According to table 1, the following relation can be obtained:

$\sum_{\mathrm{i}=0}^{\mathrm{k}} \frac{\beta^{\mathrm{i}}}{\mathrm{i} !} \frac{(\mathrm{k}+4-\mathrm{i}) !}{(\mathrm{k}-\mathrm{i}) !} \mathrm{U}(\mathrm{k}+4-\mathrm{i})+2 \beta \sum_{\mathrm{i}=0}^{\mathrm{k}} \frac{\beta^{\mathrm{i}}}{\mathrm{i} !} \frac{(\mathrm{k}+3-\mathrm{i}) !}{(\mathrm{k}-\mathrm{i}) !} \mathrm{U}(\mathrm{k}+3-\mathrm{i})+\beta^{2} \sum_{\mathrm{i}=0}^{\mathrm{k}} \frac{\beta^{\mathrm{i}}}{\mathrm{i} !} \frac{(\mathrm{k}+2-\mathrm{i}) !}{(\mathrm{k}-\mathrm{i}) !} \mathrm{U}(\mathrm{k}+2-\mathrm{i})+\lambda \mathrm{U}(\mathrm{k})-$

$\gamma \sum_{\mathrm{i}=0}^{\mathrm{k}} \frac{(\beta / 3)^{\mathrm{i}}}{\mathrm{i} !} \mathrm{U}(\mathrm{k}-\mathrm{i})=0$

This equation can be rearranged to give a recursive relation as follows:

$$
\begin{gathered}
\mathrm{U}(\mathrm{k}+4)=\frac{\mathrm{k} !}{(\mathrm{k}+4) !}\left[-\sum_{\mathrm{i}=1}^{\mathrm{k}} \frac{\beta^{\mathrm{i}}}{\mathrm{i} !} \frac{(\mathrm{k}+4-\mathrm{i}) !}{(\mathrm{k}-\mathrm{i}) !} \mathrm{U}(\mathrm{k}+4-\mathrm{i})-2 \beta \sum_{\mathrm{i}=0}^{\mathrm{k}} \frac{\beta_{\mathrm{i}}^{\mathrm{i}}}{\mathrm{i} !} \frac{(\mathrm{k}+3-\mathrm{i}) !}{(\mathrm{k}-\mathrm{i}) !} \mathrm{U}(\mathrm{k}+3-\mathrm{i})-\beta^{2} \sum_{\mathrm{i}=0}^{\mathrm{k}} \frac{\beta_{\mathrm{i}}^{\mathrm{i}} \frac{(\mathrm{k}+2-\mathrm{i}) !}{(\mathrm{k}-\mathrm{i}) !} \mathrm{U}(\mathrm{k}+2-\mathrm{i})-}{\lambda \mathrm{Uk}+\gamma \mathrm{i}=0 \mathrm{k} \beta 3 \mathrm{ii} ! \mathrm{Uk}-\mathrm{i}}\right.
\end{gathered}
$$

Normalized boundary conditions and their associated DTM transformations are presented in table 2.

\begin{tabular}{|c|c|c|}
\hline $\mathrm{BCs}$ & Original form & DTM transform \\
\hline Fixed: & $\overline{\mathbf{U}}=\frac{\mathbf{d} \overline{\mathbf{U}}}{\mathbf{d} \xi}=\mathbf{0}$ & $\begin{array}{l}\text { at } \xi=\mathbf{0}: \mathbf{U}(\mathbf{0})=\mathbf{U}(\mathbf{1})=\mathbf{0} ; \\
\text { at } \xi=1: \sum_{\mathbf{k}=\mathbf{0}}^{\infty} \mathbf{U}(\mathbf{k})=\mathbf{0} ; \sum_{\mathbf{k}=\mathbf{0}}^{\infty}(\mathbf{k}+\mathbf{1}) \mathbf{U}(\mathbf{K}+\mathbf{1})=\mathbf{0}\end{array}$ \\
\hline Simply supported: & $\overline{\mathbf{U}}=\frac{\mathbf{d}^{2} \overline{\mathbf{U}}}{\mathbf{d} \xi^{2}}=\mathbf{0}$ & $\begin{array}{l}\text { at } \xi=\mathbf{0}: \mathbf{U}(\mathbf{0})=\mathbf{U}(2)=\mathbf{0} ; \\
\text { at } \xi=1: \sum_{\mathbf{k}=0}^{\infty} \mathbf{U}(\mathbf{k})=\mathbf{0} ; \sum_{\mathbf{k}=0}^{\infty}(\mathbf{k}+\mathbf{1})(\mathbf{k}+2) \mathbf{U}(\mathbf{k}+2)=\mathbf{0}\end{array}$ \\
\hline Free: & $\frac{d^{2} \bar{U}}{d \xi^{2}}=\frac{d^{3} \bar{U}}{d \xi^{3}}=\mathbf{0}$ & $\begin{array}{l}\text { at } \xi=0: \mathbf{U}(2)=\mathbf{U}(3)=0 \\
\text { at } \xi=1: \sum_{\mathbf{k}=0}^{\infty}(\mathbf{k}+1)(\mathbf{k}+2) \mathbf{U}(\mathbf{k}+2)=0 \\
\text { at } \xi=1: \sum_{\mathbf{k}=0}^{\infty}(\mathbf{k}+\mathbf{1})(\mathbf{k}+2)(\mathbf{k}+3) \mathbf{U}(\mathbf{k}+3)=0\end{array}$ \\
\hline
\end{tabular}

Table 2: Normalized Boundary Conditions and Their Associated DTM Transformations

Now, for the sake of brevity, the solution procedure is only explained for the cantilever beam. The same procedure is valid for other boundary conditions, and in section 4 the results of all the above mentioned conditions are covered.

Eq. (11) reveals that if the first four terms were known (i.e. $U(0), U(1), U(2), U(3)$ ) all the other terms could be obtained by the recursive relation. Therefore, for the cantilever beam we have:

$\mathrm{U}(0)=\mathrm{U}(1)=0$

$\mathrm{U}(2)=\mathrm{c}_{1}, \mathrm{U}(3)=\mathrm{c}_{2}$

Here, the values of $U(2)$ and $U(3)$ are set as unknown parameters, based on which the value of $U(k)$ for $k=4,5,6 \ldots$ can now be calculated. Substituting these values in the remaining boundary conditions at $\xi=1$, and by some rearrangement we have:

$\left[\begin{array}{l}\mathrm{E}_{11} \mathrm{E}_{12} \\ \mathrm{E}_{21} \mathrm{E}_{22}\end{array}\right]\left\{\begin{array}{l}\mathrm{c}_{1} \\ \mathrm{c}_{2}\end{array}\right\}=\left[\begin{array}{l}0 \\ 0\end{array}\right]$

In which $\mathrm{E}_{\mathrm{ij}}$ is a polynomial function of $\gamma$. In order to obtain nontrivial solutions, we must equate the determinant to zero: $E_{11}(\gamma) E_{22}(\gamma)-E_{12}(\gamma) E_{21}(\gamma)=0$. The roots of this equation will ultimately give the natural frequencies.

\section{Results and discussion}

In the first step, results are compared with DQEM [6] , $4^{\text {th }}$ order Runge-Kutta and analytical solutions. Table 3 illustrates the results for a simply supported uniform beam resting on a Winkler foundation.

It is observed from table 3 that the present results from DTM are more accurate than DQEM and RK4, and very close to analytical values. In the third natural frequency, DTM results are equal to the analytical value, while DQEM [6] and RK4 show small deviations.

In table 4, the results are shown for the cantilever and fixed-fixed case, respectively. A good agreement between the results is observed. 
Table 3: Natural Frequencies of a Simply Supported Uniform Beam Resting on Winkler Foundation

\begin{tabular}{llllll}
\hline Method & $\boldsymbol{\omega}_{\mathbf{1}}$ & $\boldsymbol{\omega}_{\mathbf{2}}$ & $\boldsymbol{\omega}_{\mathbf{3}}$ & $\boldsymbol{\omega}_{\mathbf{4}}$ & $\boldsymbol{\omega}_{\mathbf{5}}$ \\
\hline DTM $(\boldsymbol{\alpha}=\mathbf{0})$ & 9.92014 & 39.4911 & 88.8321 & 157.9168 & 246.7421 \\
DQEM [6] & 9.92014 & 39.4913 & 89.4002 & - & - \\
RK4 & 9.92382 & 39.6912 & 89.4774 & 159.3005 & 249.6820 \\
\hline Exact solution & 9.92014 & 39.4911 & 88.8321 & 157.9168 & 246.7421 \\
\hline
\end{tabular}

Table 4: Natural Frequencies of a Cantilever and Fix-Fix Beam Resting on Winkler Foundation

\begin{tabular}{lllllll}
\hline Beam type & Method & $\boldsymbol{\omega}_{\mathbf{1}}$ & $\boldsymbol{\omega}_{\mathbf{2}}$ & $\boldsymbol{\omega}_{\mathbf{3}}$ & $\boldsymbol{\omega}_{\mathbf{4}}$ & $\boldsymbol{\omega}_{\mathbf{5}}$ \\
\hline \multirow{3}{*}{ cantilever } & DTM $(\alpha=0)$ & 3.65546 & 22.0572 & 61.7053 & 120.906 & 199.862 \\
& DQEM [6] & 3.65544 & 22.0572 & 61.7057 & 120.911 & 199.894 \\
& RK4 & 3.65563 & 22.0954 & 61.9724 & 121.039 & 200.264 \\
fixed- fixed & DTM $(\alpha=0)$ & 22.3956 & 61.6809 & 120.9075 & 199.862 & 298.557 \\
& DQEM [6] & 22.3956 & 61.6811 & 120.910 & 199.885 & 298.675 \\
& RK4 & 22.40599 & 61.84613 & 122.04241 & 202.05676 & 301.86977 \\
\hline
\end{tabular}

In the next step, natural frequencies are calculated for different values of $\alpha$. In order to show the accuracy of the results, the convergence of the solution should be examined. The convergence of the first five natural frequencies with respect to the number of terms, $N$, is depicted for the cantilever boundary condition in Fig. 2.

(a)
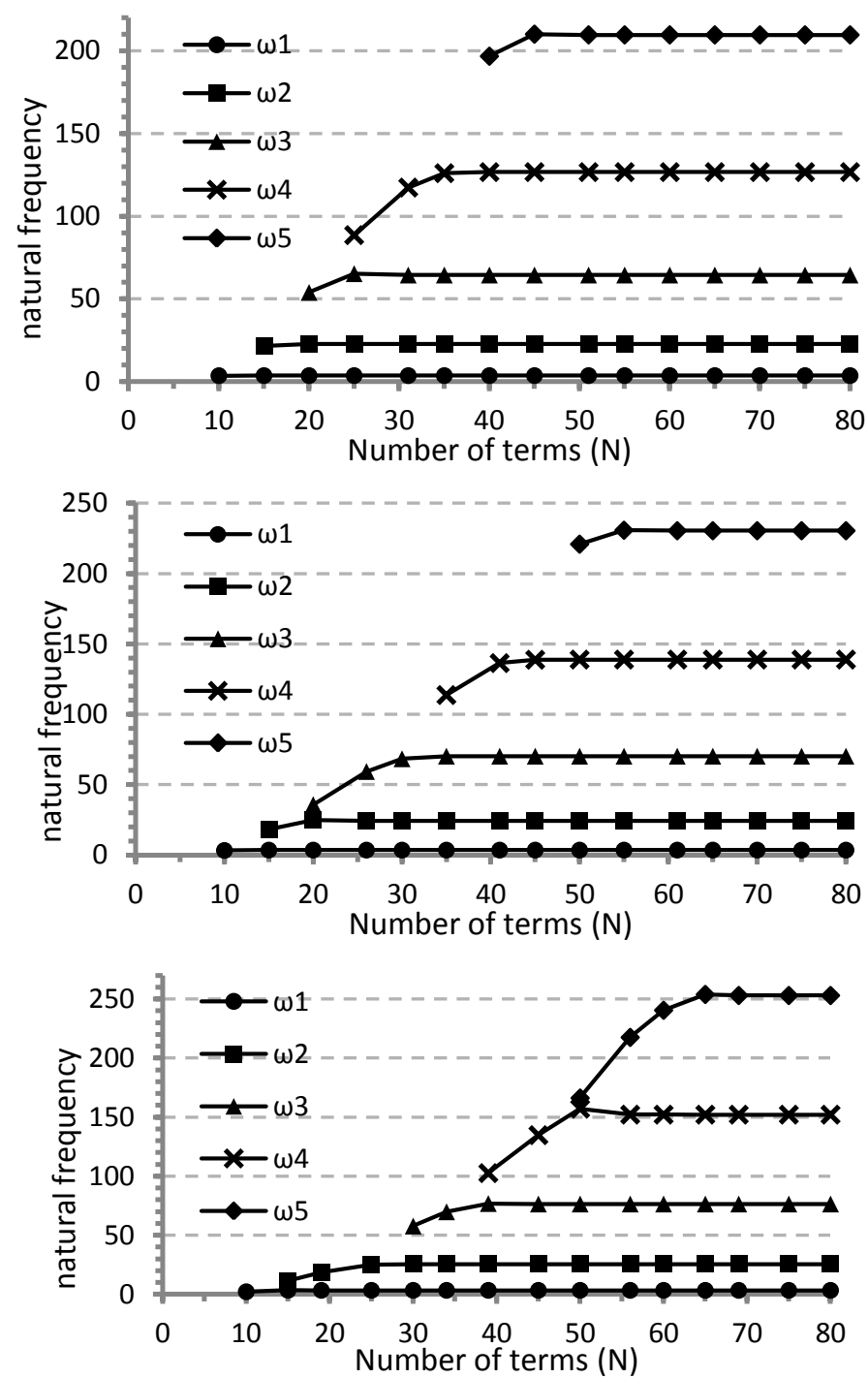

Fig. 2: Convergence of $\gamma$ Vs. $N$ for Cantilever Beam a) $\alpha=0.1$, b) $\alpha=0.3$, c) $\alpha=0.5$

Two conclusions can be drawn from Fig. 2. First, to obtain higher natural frequencies more terms should be considered. For example, while $N=10$ leads to valid fundamental frequency, $N=80$ should be chosen for the fifth natural frequency. Second, increasing the value of $\alpha$ will delay the convergence. For instance, in order to get a four-digit precision in the 
fifth natural frequency, computation of only 55 terms is sufficient for $\alpha=0.1$ (Fig. 2-a) while, this number increases to around 80 for $\alpha=0.5$ (Fig. 2-c). In fact, higher values of $\alpha$, leads to faster exponential changes in the thickness, and more terms are needed for convergence.

Finally, table 5 shows the natural frequencies of the exponential beam for different values of $\alpha$ and different boundary conditions. Choosing the right number of terms $(N)$ depends on the value of $\alpha$, the desired precision and the number of natural frequencies to be obtained. Here, all calculations were performed so that the results are independent of $N$.

Table 5: Natural Frequencies of an Exponential Beam for Different Values of $\alpha$

\begin{tabular}{|c|c|c|c|c|c|c|c|}
\hline \multirow{2}{*}{\multicolumn{2}{|c|}{$\begin{array}{l}\text { Exponential parameter } \\
\qquad \boldsymbol{\alpha}\end{array}$}} & \multicolumn{3}{|c|}{ fixed-fixed } & \multicolumn{3}{|c|}{ simply-simply } \\
\hline & & $\omega_{1}$ & $\omega_{2}$ & $\omega_{3}$ & $\omega_{1}$ & $\omega_{2}$ & $\omega_{3}$ \\
\hline \multirow{2}{*}{-0.2} & DTM & 20.2933 & 55.8197 & 109.3690 & 8.9686 & 35.7183 & 80.3320 \\
\hline & RK4 & 20.31180 & 56.14303 & 110.01789 & 8.97094 & 35.85730 & 81.40257 \\
\hline \multirow{2}{*}{-0.1} & DTM & 21.3125 & 58.6755 & 115.0026 & 9.4379 & 37.5621 & 84.4878 \\
\hline & RK4 & 21.33475 & 59.06035 & 116.03771 & 9.44097 & 37.73107 & 85.83340 \\
\hline \multirow{2}{*}{0} & DTM & 22.3956 & 61.6809 & 120.9075 & 9.9201 & 39.4911 & 88.8321 \\
\hline & RK4 & 22.40599 & 61.84613 & 122.04241 & 9.92382 & 39.69120 & 89.47743 \\
\hline \multirow{2}{*}{0.1} & DTM & 23.5469 & 64.8439 & 127.0962 & 10.4145 & 41.5085 & 93.3717 \\
\hline & RK4 & 23.59329 & 65.62659 & 129.97674 & 10.41866 & 41.74078 & 95.34377 \\
\hline \multirow{2}{*}{0.3} & DTM & 26.0737 & 71.6765 & 140.3752 & 11.4363 & 45.8224 & 103.0659 \\
\hline & RK4 & 26.13118 & 72.72102 & 144.00256 & 11.44065 & 46.12065 & 105.78168 \\
\hline \multirow{2}{*}{0.5} & DTM & 28.9369 & 79.2460 & 154.9464 & 12.4959 & 50.5314 & 113.6291 \\
\hline & RK4 & 29.00333 & 80.59243 & 159.74265 & 12.49926 & 50.89548 & 117.22874 \\
\hline
\end{tabular}

In addition, the first three vibrational mode shapes for different values of $\alpha$ are depicted in Fig. 3-5 for the different boundary conditions. It is observed that the value of $\alpha$ directly affects the vibrational modes of the beam as expected.
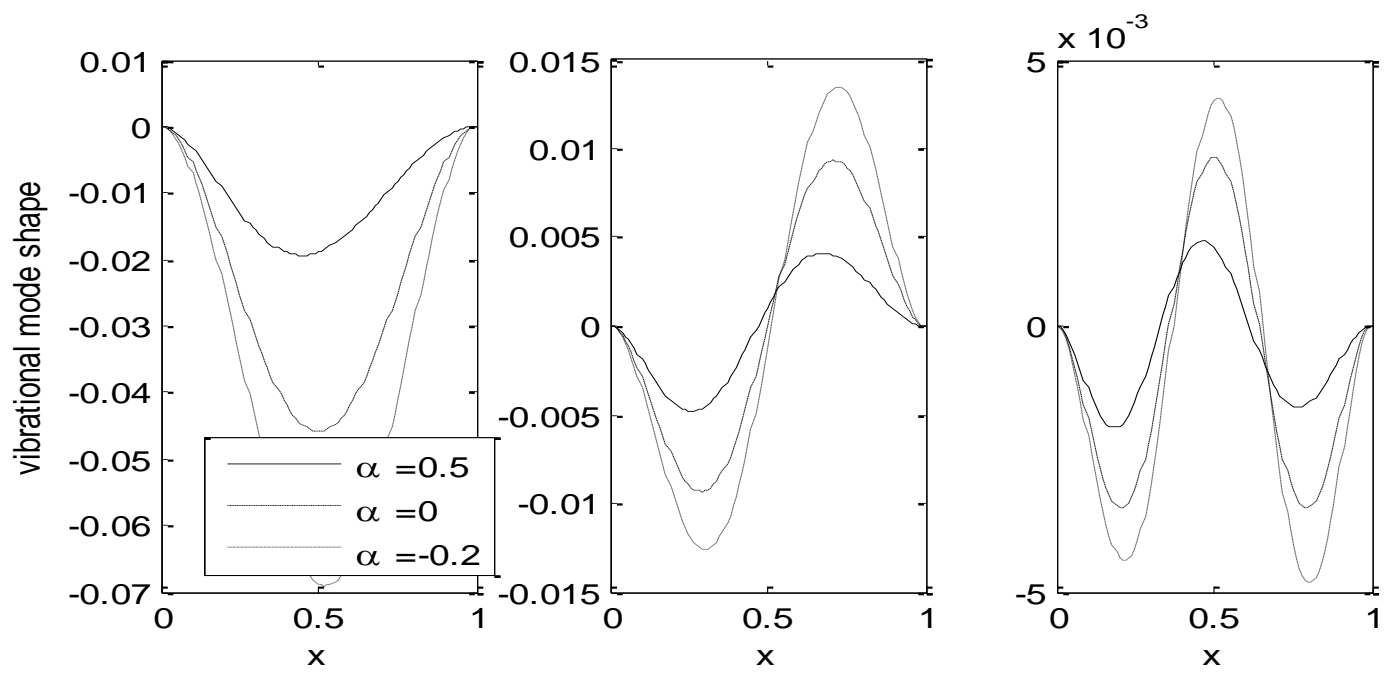

Fig. 3: The First Three Vibrational Modes for the Fixed-Fixed Boundary Condition
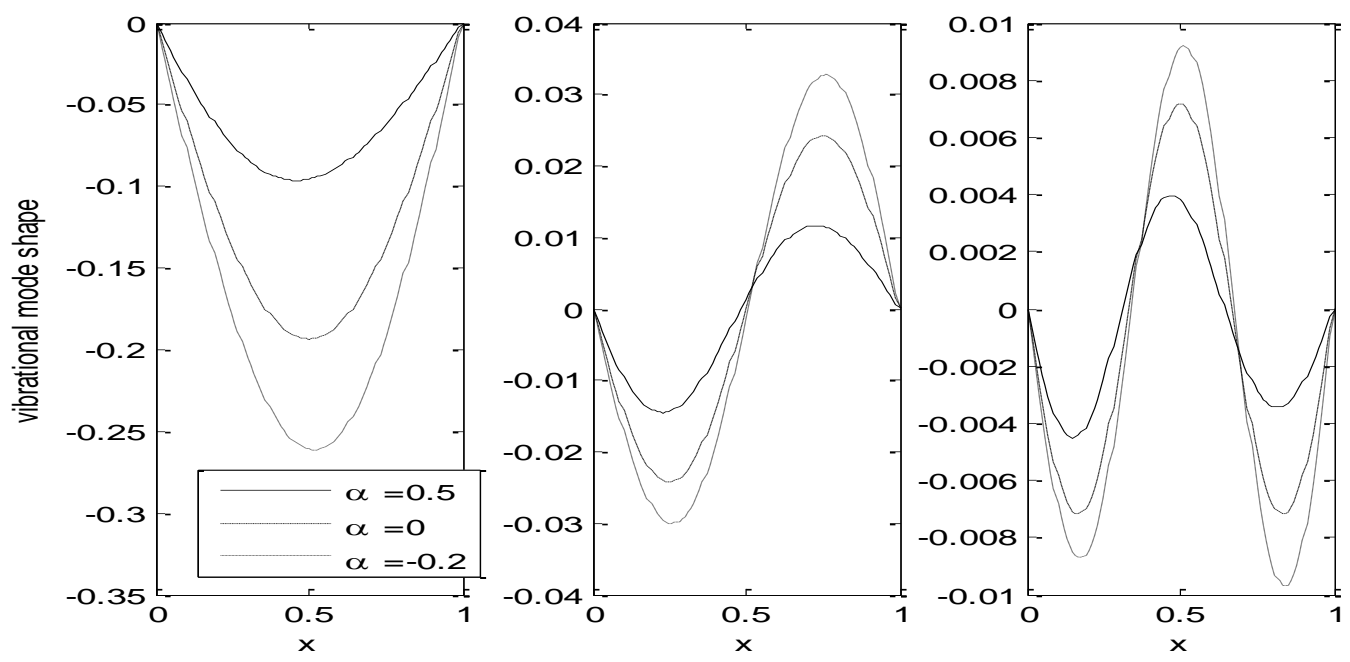

Fig. 4: The First Three Vibrational Modes for the Simply Supported Boundary Condition 

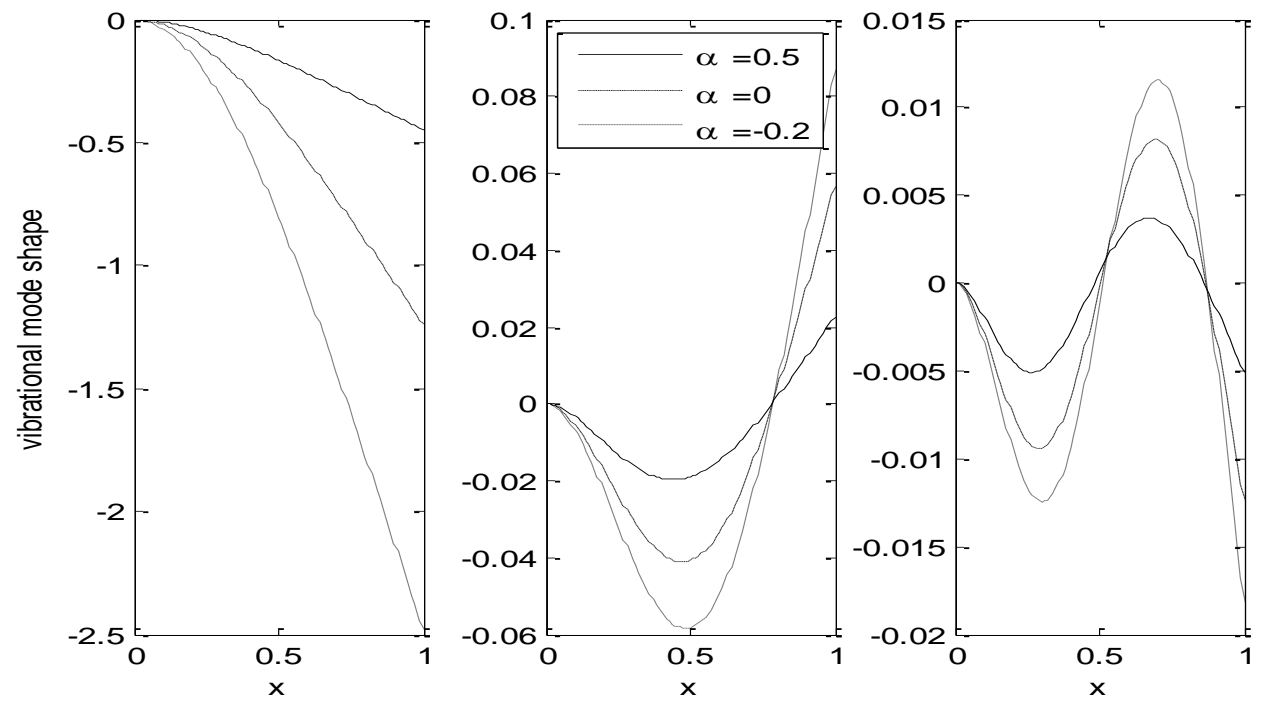

Fig. 5: The First Three Vibrational Modes for the Cantilever Boundary Condition

\section{Conclusion}

In this study, the vibration analysis of a new type tapered beam, exponential Euler-Bernoulli beam, supported by a Winkler foundation was investigated using a semi-analytical method, the DTM. Natural frequencies of the beam were obtained by use of this method, and the convergence of the results for different values of exponential factor $(\alpha)$ was examined. Comparisons were made with DQEM from the literature, $4^{\text {th }}$ order Runge-Kutta and exact solution, and excellent agreement was observed. The DTM was seen to be more accurate and computationally more cost effective than these two methods.

\section{References}

[1] Y.K. Lin, "Free vibrations of a continuous beam on elastic supports", International Journal of Mechanical Sciences, Vol.4, No.5, pp.409-423 (1962). Available online: http://www.sciencedirect.com/science/article/pii/S0020740362800277.

[2] A.J. Valsangkar, R. Pradhanang, "Vibration of beam-columns on two-parameter elastic foundations", Earthquake Engineering and Structural Dynamics, Vol.16, pp.217-225 (1988). Available online: http://onlinelibrary.wiley.com/doi/10.1002/eqe.4290160205/abstract.

[3] C. Franciosi, A. Masi, "Free vibrations of foundation beams on two-parameter elastic soil", Computers \& Structures, Vol.47, No.3, pp.419426 (1993). Available online: http://www.sciencedirect.com/science/article/pii/0045794993902378.

[4] M.A. De Rosa, "Free vibration of Timoshenko beams on two-parameter elastic foundation", Computers \& Structures, Vol.57, No.1, pp.151156 (1995). Available online: www.sciencedirect.com/science/article/pii/004579499400594S.

[5] P. Ruta, "The application of Chebyshev polynomials to the solution of the nonprismatic Timoshenko beam vibration problem", Journal of Sound and Vibration, Vol.296, pp.243-263 (2006). Available online: http://www.sciencedirect.com/science/article/pii/S0022460X06002100.

[6] C.N. Chen, "Vibration of prismatic beam on an elastic foundation by the differential quadrature element method", Computers \& Structures, Vol.77, No.1, pp.1-9 (2000). Available online: http://www.sciencedirect.com/science/article/pii/S0045794999002163.

[7] W.Q. Chen, C.F. Lü, Z.G. Bian, "A mixed method for bending and free vibration of beams resting on a Pasternak elastic foundation", Applied

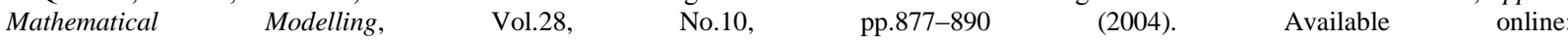
http://www.sciencedirect.com/science/article/pii/S0307904X04000605.

[8] R.J. Hosking, S.A. Husain, F. Milinazzo, "Natural flexural vibrations of a continuous beam on discrete elastic supports", Journal of Sound and Vibration, Vol.272, No.1-2, pp.169-185 (2004). Available online: www.sciencedirect.com/science/article/pii/S0022460X03003250.

[9] J.K. Zhou, Differential Transform and Its Applications for Electrical circuits, (in chinese), Huazhong University press, Wuhan China, 1986.

[10] S. Çatal, "Solution of free vibration equations of beam on elastic soil by using differential transform method", Applied Mathematical Modelling, Vol.32, No.9, pp.1744-1757 (2008). Available online: http://www.sciencedirect.com/science/article/pii/S0307904X07001357.

[11] M. Balkaya, M.O. Kaya, A. Sağlamer, "Analysis of the vibration of an elastic beam supported on elastic soil using the differential transform method”, Archive of Applied Mechanics, Vol.79, No.2, pp.135-146 (2009). Available online: http://link.springer.com/article/10.1007/s00419008-0214-9.

[12] T.O. Awodola, "Variable Velocity Influence on the Vibration of Simply Supported Bernoulli - Euler Beam under Exponentially Varying Magnitude Moving Load", Journal of Mathematics and Statistics, Vol.3, No.4, pp.228-232 (2007). Available online: http://www.thescipub.com/abstract/10.3844/jmssp.2007.228.232.

[13] Q. Mao, S. Pietrzko, "Free vibration analysis of a type of tapered beams by using Adomian decomposition method", Applied Mathematics and Computation, Vol.219, No.6, pp.3264-3271 (2012). Available online: http://www.sciencedirect.com/science/article/pii/S0096300312009812.

[14] F. Ayaz, "On the two-dimensional differential transform method", Applied Mathematics and Computation, Vol.143, No.2-3, pp.361-374 (2003). Available online: http://www.sciencedirect.com/science/article/pii/S0096300302003685.

[15] F. Ayaz, "Solutions of the system of differential equations by differential transform method", Applied Mathematics and Computation, Vol.147, No.2, pp.547-567 (2004). Available online: http://www.sciencedirect.com/science/article/pii/S0096300302007944.

[16] Arikoglu, I. Ozkol, "Solution of differential-difference equations by using differential transform method", Applied Mathematics and Computation, Vol.174, No.2, pp.1216-1228 (2006). Available online: http://www.sciencedirect.com/science/article/pii/S0096300305005436. 